\title{
Comparative bioassay of chlordiazepoxide and amylobarbitone sodium therapies in patients with anxiety states using physiological and clinical measures
}

\author{
M. H. LADER AND LORNA WING \\ From the Institute of Psychiatry, Maudsley Hospital, London, and the Department of \\ Pharmacology, University College, London
}

The experiments to be described in this paper are the extension of a series of studies on patients with anxiety states reported previously (Lader and Wing, 1964; Wing and Lader, 1965). In all of these experiments, the palmar skin resistance was recorded during a standard procedure - a rest period of 10 minutes followed by a stimulation period in which 20 identical auditory stimuli were applied automatically at intervals varying from 45 to 80 seconds. Three aspects of the skin resistance were studied in each experiment. First, the background level was analysed as its reciprocal, skin conductance, to give a measure of normal continuing sweat-gland activity. Secondly, the responses to the auditory stimuli were quantified and it was found that these responses (psychogalvanic reflexes) tended to diminish with repetition of the stimuli, i.e., habituation occurred. Thirdly, spontaneous skin conductance fluctuations were counted; these are transient fluctuations in the level of sweat-gland activity occurring independently of any external stimuli.

In the first series of experiments (Lader and Wing, 1964), the skin resistance was recorded in 20 patients with anxiety states and in 20 normal subjects matched for age and sex. In the second series (Wing and Lader, 1965) the same 20 patients were placed on a week of treatment with amylobarbitone sodium $65 \mathrm{mg}$. three times a day and a week of placebo treatment in a balanced cross-over design with double-blind control. Physiological recordings were carried out at the end of each week's therapy. It was found that the background skin conductance level during the recording dropped in the normal subjects but rose in the anxious patients. With placebo, the conductance level of the patients still tended to rise but with the barbiturate the conductance tended to drop, i.e., the barbiturate had a partial 'normalizing' effect. Habituation of the psychogalvanic reflexes was much slower in the patients than in the normals; the rate was slightly accelerated by amylobarbitone sodium. There was a greatly increased frequency of spontaneous fluctuations in the group of patients; the barbiturate lessened the number as compared with the placebo control. Thus, physiological differences existed between patients with anxiety states and normal control subjects; the differenceso were lessened by barbiturate therapy.

Clinical data also were utilized in the second study The patients made daily ratings of the severity of their symptoms and weekly ratings of changes in the same symptoms were made at interview. The symptoms were classified into four categories。 physical (autonomic or muscular), general feelings of anxiety, situational anxiety, and depressive symp? toms. The physical symptoms were the only ones to $\overrightarrow{0}$ show significant improvement on the drug as compared with placebo.

From the above studies, it appeared that the physiological measures, at least, were sensitive to the action of sedative drugs. It was decided to apply the techniques to the problem of the comparison of two drugs used in the treatment of anxiety states. One drug was amylobarbitone sodium, widely accepted as offering partial symptomatic relief (Editorial, 1962) and which had been used already. This was the 'standard'. The other drug, the 'unknown', was chlordiazepoxide (Librium) quite recently introduced and claimed by some to have special 'anxiolytic' properties. It has enjoyed a great vogue but its superiority over the well-tried barbiturates has never $\delta$ been convincingly demonstrated. A typical comparative trial, well carried out, compared chlor- 을 diazepoxide, $20 \mathrm{mg}$. three times a day, with amylo- $>$ barbitone sodium, $65 \mathrm{mg}$. three times a day (Jenner, Kerry, and Parkin, 1961). The authors concluded $\mathrm{N}$ that chlordiazepoxide was superior to the barbitu- $\Omega$ rate in the dosages used. Thus, no definite conclusion $N$ regarding the general efficacies of the two drugs could $N_{\omega}$ 414 
be drawn from this experiment. If only one dose of each drug is used, the comparison of therapeutic effects is confounded by dosage differences.

A substantial portion of pharmacological theory and practice is devoted to this very problem of comparing two drugs, usually an 'unknown' in terms of a 'standard'. In these comparisons, the minimum requirement is that two dose levels of one drug be used but more dosage levels provide more accurate dose-effect curves and hence increased precision.

The purpose of this paper is to present the results of a formal bioassay of sedative drug therapy in patients with anxiety states. Two dose levels of amylobarbitone sodium, two dose levels of chlordiazepoxide, and a placebo were given, i.e., a twoplus-two-plus-one slope-ratio bioassay design was utilized. However, before this full-scale bioassay could be started it was necessary to know roughly the relative potencies of the two drugs so that the dosage levels would be approximately equivalent. Therefore, a preliminary matching assay was carried out using the sequential 'staircase' or 'up-and-down' method (Dixon and Mood, 1948; Brownlee, Hodges, and Rosenblatt, 1953). Thus, the results section consists of two parts, an account of the preliminary matching assay followed by the results of the formal sloperatio bioassay. Both physiological and clinical data are presented in each part.

\section{PATIENTS}

Patients suffering from anxiety states presenting at the Maudsley Hospital as new out-patients were asked to participate in the study. They were informed of the research nature of the trial and their right to refuse to take part or to withdraw at any time was emphasized. In the 'staircase' assay, eight patients participated, five male and three female; a further 30 patients took part in the main assay of whom 19 were men.

All the patients included complained of symptoms of anxiety either 'free-floating' (present continuously) or 'situational' (present only in specific situations). The diagnostic criteria were widened somewhat as compared with those in the earlier study (Lader and Wing, 1964) both in order to try the drugs on a wider range of patients and to obtain sufficient patients in a reasonable time; patients with a greater admixture of depressive features were included as were patients with previously abnormal personalities. Thus, in the preliminary assay, two men suffered from free-floating anxiety whilst the other three men had situational anxiety. Two women had situational anxiety and one complained of symptoms of anxiety with depression. In the main assay, eight men had free-floating anxiety, seven situational anxiety, and four anxiety with depression; in four of the male patients, the pre-morbid personality was abnormal. Of the female patients, one had free-floating anxiety, five situational anxiety, and five anxiety with depression. One woman had an abnormal personality. The respective consultants in charge of each patient regarded treatment with sedatives as being firmly indicated. No other treatment was given during the course of the trial and any previous drug treatment was terminated a few days before this trial.

The ages of the patients ranged from 20 to 47 and the duration of illness from one month to 18 years.

\section{PHYSIOLOGICAL MEASURES}

MEASUREMENT OF SKIN RESISTANCE The technique for the recording of the skin resistance has been fully detailed in a previous report (Lader, 1964) and the following is a summary.

Two double-element electrodes made of lead were used: the inactive one was placed on an abraded area of the right arm above the elbow; the active electrode site was the distal phalanx of the right thumb on which was placed an annular foam plastic cornplaster (internal diameter $9.5 \mathrm{~mm}$.) as a masking device. Electrode jelly containing $0.05 \mathrm{M}$ sodium chloride was used at both sites. A constant current of 10 microamperes was passed through the electrodes and the voltage engendered (which was proportional to the resistance at the active electrode site) was balanced back in steps of $0.25 \mathrm{v}$ (equivalent to 25 kilohms). The residual voltage was led into a Grass driver amplifier and hence to a Grass ink-writing penoscillograph with a paper chart speed of $1.5 \mathrm{~mm}$. $/ \mathrm{sec}$. Full-scale deflection sensitivities of $\pm 100, \pm 50$, and \pm 25 kilohms were available.

STIMULATION PROCEDURE Twenty identical auditory stimuli were presented automatically at intervals varying randomly from 45 to 80 seconds. Each stimulus was a 1,000 c.p.s. pure tone of one second duration standardized as one volt across a $3 \mathrm{ohm}$ loudspeaker placed $30 \mathrm{~cm}$. above and $30 \mathrm{~cm}$. behind the patient's head. Using a Dawes sound-level meter, the intensity of the sound was $100 \mathrm{db}$ above a reference source of 0.0002 dynes/sq. $\mathrm{cm}$.

EXPERIMENTAL CONDITIONS The patient sat in a comfortable armchair in a sound-protected room, the temperature of which was controlled at 22 to $24^{\circ} \mathrm{C}$. Leads passed through a wall to the recording equipment in an adjoining room from which the recordist could observe the patient through a one-way screen. The patients were informed that they would be under observation.

RECORDING PROCEDURE The electrodes were applied and the patient was asked to make himself as comfortable as possible and to relax as far as he was able. The right of every patient to withdraw at any stage of the test was emphasized. (No one in fact withdrew.) The patient was told that there would be a rest period of several minutes followed by a series of sounds to which he was to make no active response.

The room lights were dimmed, the patient was left alone, and recording was started. After 11 minutes, the 20 auditory stimuli were applied in sequence and recording was terminated one minute after the last stimulus.

ANALYSIS OF SKIN RESISTANCE RECORDINGS From the previous studies (Lader, 1964; Wing and Lader, 1965), it was known that three variables were the most sensitive 
to drug effects. The derivation of these variables was complex and full details are given elsewhere (Lader and Wing, 1964). The following is a résumé.

Change in conductance level from beginning to end of experiment ('total conductance change') Four skin resistance levels were read off at minute intervals from the start of the experiment. These readings (in kilohms) were converted to log conductance values (in log micromhos) and averaged to give the mean log conductance level at the beginning of the experiment. The resistance levels immediately before each of the last three stimuli plus the level at the very end of the recording were read off, converted to $\log$ conductance, and averaged. This mean value was subtracted from the mean level at the beginning of the experiment to yield the 'total conductance change' throughout the experiment. Being a change in log and hence the log of a ratio, the variable is dimensionless.

In the previous experiments, the effect of a barbiturate had been to increase the magnitude of this variable.

Rate of habituation of the psycho-galvanic reflexes ('H-score') The psycho-galvanic reflexes were usually clear-cut diminutions in skin resistance so that readings were made at the start and at the lowest point of each psycho-galvanic reflex. The readings were individually converted to the $\log$ conductance values and the value at the start of the response was subtracted from that at the lowest point to give the psycho-galvanic reflex quantified in terms of change in log conductance. Thus, 20 responses were obtained from each recording.

It was known from the previous studies that the responses tended to diminish as the stimuli continued, i.e., habituation occurred. Furthermore, whilst the first response was distinct, responses two to 20 tended to follow an exponential course. Therefore, if the responses for each experiment were plotted as the ordinate with the logarithm of the stimulus number as the abscissa, a

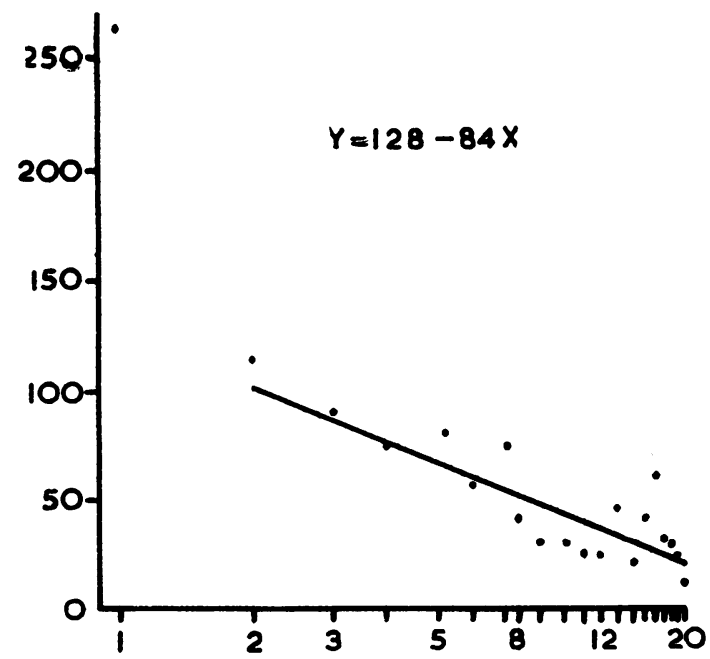

FIG. 1. Example of habituation regression line. Abscissa is stimulus number plotted on a logarithmic scale. Ordinate is magnitude of psychogalvanic reflex $\times 10^{-3}$. straight line course was apparent. An example is shown in Figure 1. By routine statistical techniques (Snedecor, 1956), the equation for the regression line of responses on log stimulus number can be calculated. In the example given the equation is

Response $(Y)=10^{-3}(128-84$ log. stimulus no. $(X))$ The constant $10^{-3} \times 128$ represents ' $a$ ', the $Y$-intercept, i.e., the point on the $Y$ axis which would be intersected by the regression line if it were extrapolated to the left to the $\mathrm{X}=\mathbf{0}$ position (stimulus one). The larger the a-value, the greater the earlier responses. The constant $10^{-3} \times-84$ represents the 'b-value', the regression coefficient or slope of the line. The more negative is ' $b$ ', the steeper is the slope of the line and the more rapid is habituation.

In some experiments, the responses habituated to zero before the end of the sequence of stimuli. An arbitrary criterion was adopted for assessing such complete habituation: if three successive stimuli failed to elicit a discernible response, habituation was deemed complete. Thus, the third zero response was regarded as the end of the response series when calculating the regression line equation.

For every experiment, a regression equation, each with an a-value and a b-value was calculated. Next, a significant negative correlation between the a-values and the b-values was found for each series of experiments. This signified that rapid habituation (in absolute terms tended to follow on large early responses. Routine regression techniques were used to remove this depend@ ence so that a corrected rate of habituation was calculated The value obtained was termed an $\mathrm{H}$-score and the more negative the value, the more rapid was habituation. In the previous experiments, barbiturates accelerated habituation, i.e., made the $\mathrm{H}$-score more negative.

Spontaneous skin conductance fluctuations at end experiment ('fluctuations at end') Skin resistance. fluctuations above a certain criterion of magnitude were c counted during the 40 -second periods before each of the last seven stimuli and for the last $\mathbf{4 0}$ seconds of the experiment (320 seconds in all). The counts were totalled to give one score. The criterion used was $0.003 \mathrm{log}$ micromhos and the technique for applying this log conductance criterion to a resistance recording has been detailed elsewhere (Lader, 1964).

In the previous experiments, the number of fluctuations was decreased by a barbiturate as compared with a placebo.

\section{CLINICAL MEASURES}

DAILY SELF-RATING OF SYMPTOMS At the first interview, the patient listed his symptoms in his own words, e.g., 'feeling of fear', and these symptoms were entered onto a special form. Opposite each symptom was a horizontal line $10 \mathrm{~cm}$. long. The patient rated the average severity of each symptom during the previous few days by placing a mark anywhere along each line which was marked 'absent' at the left, 'moderate' in the centre, and 'very severe' at the right. This rating was designated 'baseline'.

The patient was given a week's supply of forms each typed with his symptom inventory and individually dated. He was instructed to complete one each evening assessing 
the severity of each symptom during the preceding 24 hours. No reference was to be made to the previous days' forms.

Analysis of daily rating scales The distance from the left of the line to the patient's mark was measured to the nearest centimetre. As each patient had an individual symptom list, direct comparisons of the raw data were impracticable. However, it was noted that all the symptoms could be grouped into four categories: 1 Physical symptoms (autonomic or muscular such as palpitations or shakiness); 2 general anxiety ('feeling of fear', etc.); 3 situational anxiety, i.e., anxiety experienced in special situations such as public transport; 4 depressive symptoms.

Inspection of the data showed that each patient's symptom ratings classified under the same heading were sufficiently close to allow them to be combined to give one mean score for each category. If a symptom category was not represented, e.g., some patients had no general anxiety symptoms, a score of zero was assigned to it.

The mean score for each category was computed from the ratings of only the last three days of each treatment week. This allowed for the build-up of drug effects and also for the dissipation of any possible carry-over effect from the previous week's treatment. Thus, for each patient, one score was obtained for each symptom category for each week of treatment. These scores were subtracted from the corresponding baseline scores to give indices of change. A positive index indicated clinical improvement, a negative one worsening of symptoms.

WEEKLY RATING OF SYMPTOMS BY A PSYCHIATRIST At the end of each week after the recording session, the patients were interviewed (by L.W.) to ascertain if there had been any change in the severity of their symptoms as compared with the pre-treatment level. A nine-point scale was used to rate each symptom: +4 as much improved through 0 no change to -4 much worse. These scores were averaged into the four categories. As they were already in the form of changes from pre-treatment state, no further correction was required.

SIDE-EFFECTS At the end of the interview each week, the patient was asked if he had experienced any untoward effects, such as drowsiness, which he attributed to the tablets.

\section{'STAIRCASE' ASSAY}

DRUG DOSAGE AND EXPERIMENTAL DESIGN Specially prepared white sugar-coated tablets containing $65 \mathrm{mg}$. of amylobarbitone sodium were provided. Matching tablets of chlordiazepoxide were available in five strengths: $5 \mathrm{mg}$., $7.5 \mathrm{mg}$., $10 \mathrm{mg}$., $12.5 \mathrm{mg}$., and $15 \mathrm{mg}$.

Each of the eight patients received two weeks of drug treatment; during one week the drug was amylobarbitone sodium, $65 \mathrm{mg}$. three times a day (approximately 200 mg. a day). Half of the patients were given the barbiturate during the first week, half during the second. For the other week, chlordiazepoxide was given in a dosage depending on the results obtained with the preceding patient. If that patient's dose of chlordiazepoxide was more powerful than the standard dose of amylobarbitone sodium (as assessed by the D-score-see results section), the subsequent patient was given a smaller dose of chlordiazepoxide, and vice versa.

The dosages of chlordiazepoxide administered were in chronological order: $5 \mathrm{mg}$. twice a day, $20 \mathrm{mg}$., $15 \mathrm{mg}$., $5 \mathrm{mg}$., $7.5 \mathrm{mg}$., $10 \mathrm{mg}$., $15 \mathrm{mg}$., and $12.5 \mathrm{mg}$., all three times a day. The first two patients were already on chlordiazepoxide when asked to take part in the trial but they refused to discontinue their drugs although they agreed to try another drug for one week only. As this staircase assay was intended to be merely a preliminary, approximate match, these patients were accepted on these terms. The other six patients were removed from any medication for at least 48 hours before the trial started. They were unaware that two drugs would be given but were told that we were interested in their opinions of some tablets which they might find helpful. The trial was only singleblind as the investigators had to fix the dosage and order of administration of the drugs for each patient.

At the beginning of the trial, the patient was given a week's supply of tablets. No symptom-inventory forms were supplied as we were interested only in the global self-assessment of the patient in this preliminary assay. At the end of the first week, the physiological recording procedure was carried out and the second week's tablets were given. A week later, the patient re-attended and was re-tested. He was then told that he had actually received two different drugs and he was asked which week's treatment he preferred for the overall control of his symptoms.

RESULTS OF PHYSIOLOGICAL MEASURES Two sets of physiological data were obtained for each patient, one with barbiturate and one with chlordiazepoxide. Each set of data consisted of three scores: total conductance change, $\mathbf{H}$-score, and fluctuations at the end. From previous work it was known that these variables could be combined to yield one score which yielded high discrimination between a group of patients with anxiety states and a group of normal control subjects (Lader and Wing, 1964) and also gave high discrimination in those patients between barbiturate therapy and placebo therapy (Wing and Lader, 1965). The technique used was 'discriminant function analysis' (Fisher, 1954) and the equation derived was

Discriminant-function score (D-score) $=-0.074$ (total conductance change) $+\mathbf{0 . 4 8 5}$ (H-score) +

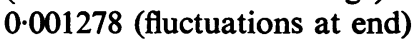

The higher the D score, the greater is 'composite physiological activity'. Patients with anxiety states were found to have higher $D$ scores than normal subjects and treatment with amylobarbitone sodium was found to lower the D scores.

In the present experiment, the data for each patient were inserted into the above equation to yield two D scores, one after a week's treatment with $200 \mathrm{mg}$ a day of amylobarbitone sodium (D amylobarb.) 
and one after a week of therapy with chlordiazepoxide (D chlordiaze.). The larger of the two scores could be regarded as reflecting greater 'composite physiological activity' on that occasion, i.e., the drug therapy had been less effective. Next, D amylobarb. was subtracted from the corresponding D chlordiaze. score: if the difference was positive, it signified that the barbiturate had been more effective than the chlordiazepoxide; if negative, the amylobarbitone sodium, $200 \mathrm{mg}$. a day, had been less efficacious than the dose of chlordiazepoxide.

The D score differences were plotted out against the total daily dosages of chlordiazepoxide (Fig. 2). To the left, in the low dosage range of chlordiazepoxide, the difference scores are positive, i.e., chlordiazepoxide was the weaker drug; to the right in the high dosage range, some negative difference scores are obtained. A regression line was calculated (Snedecor, 1956) and the equation for regression of D score difference $(Y)$ on chlordiazepoxide dose $(X)$ is:

$$
Y=10^{-3}(46 \cdot 8-1 \cdot 36 X)
$$

putting $Y=0, X=34 \cdot 4$. That is, when there is no difference between the two drugs regarding their physiological effects, $200 \mathrm{mg}$. a day of amylobarbitone sodium is equivalent to $34.4 \mathrm{mg}$. a day of chlordiazepoxide.

The regression line is significant $(P<0.025)$ and the 0.05 confidence limits of error were calculated. From them, it was found that the limits of error for the equivalent dosage were $24.5 \mathrm{mg}$. and $45.8 \mathrm{mg}$. In other words, there is only a one in twenty chance that the total daily dose of chlordiazepoxide which is equivalent to $200 \mathrm{mg}$. daily of amylobarbitone sodium lies outside the values of $24.5 \mathrm{mg}$. and $45.8 \mathrm{mg}$.

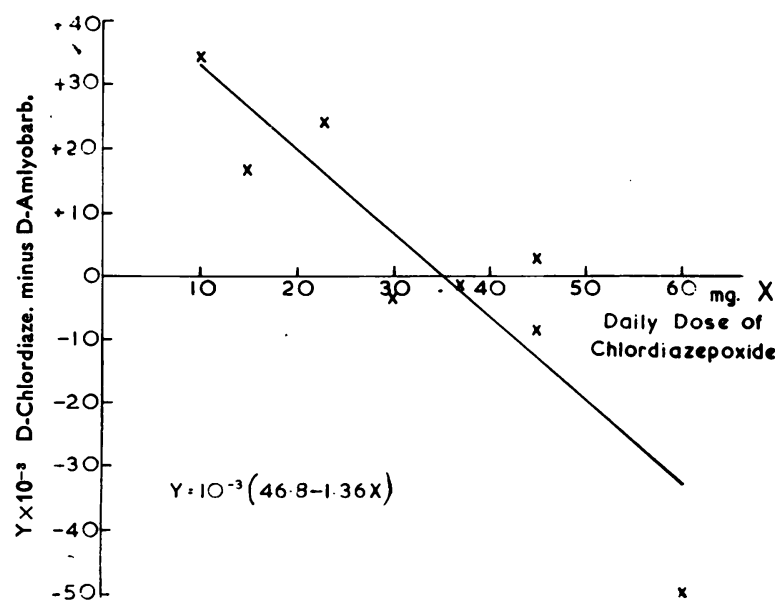

FIG. 2. Regression line for 'staircase' bioassay.
PREFERENCE OF PATIENTS The patients given the three weakest dosage levels of chlordiazepoxide preferred the barbiturate on a global self-assessment (Table I). Conversely, those patients given $45 \mathrm{mg}$. or $60 \mathrm{mg}$. a day of chlordiazepoxide regarded it as superior to amylobarbitone sodium. Two patients, on $30 \mathrm{mg}$. and $37.5 \mathrm{mg}$. a day of chlordiazepoxide, were unable to come to any decision, which suggests that this dosage range is roughly equivalent clinically to $200 \mathrm{mg}$. of amylobarbitone sodium; this confirms the laboratory results.

FORMAL SLOPE-RATIO BIOASSAY

DRUG DOSAGE AND EXPERIMENTAL DESIGN The dosages chosen for the formal assay were based on the equivalent doses of the two drugs obtained from the staircase assay. The two dose levels of amylobarbitone were $50 \mathrm{mg}$. three times a day and $100 \mathrm{mg}$. three times a day. For chlordiazepoxide, the dosage schedules were $7.5 \mathrm{mg}$. three times a day and $15 \mathrm{mg}$. three times a day. The doses of the barbiturate, chlordiazepoxide, and a lactose placebo were made up into identical-looking white sugar-coated tablets.

A balanced randomized incomplete block design was used in which each of the 30 patients received three out of the five possible treatments, one during each of threes successive weeks. Thus, each treatment was given to $18 \frac{\text { () }}{\mathrm{D}}$ patients. The order of administration was balanced fore weeks so that each treatment was given to six patients ? the first week, six the second week, and six the third week. Furthermore, possible carry-over effects were balancedo out by having every treatment follow every other treatment an equal number of times. The patients were allotted to their treatment schedules according to a code held bythe hospital pharmacist so that the experiment was carried out 'double-blind' in its entirety. The patients were not aware that different treatments were to be given each week but were told at the start of the trial that we were interested in the effects of some tablets which might alleviate their symptoms.

EXPERIMENTAL PROCEDURE At the patient's first attendance, the physiological recording procedure was carried out. (The results from these pre-drug recordings will not be presented in this paper.) The patient then completed his baseline symptom inventory sheet. He was given seven of these rating forms and a week's supply of tablets. A week later, he returned at the same time of day, the second recording procedure was performed and the rating of the changes in symptoms with the first week's treatment was made (by L.W.). The second week's tablets and forms were given. At the end of the second week, the third recording was made and the symptoms re-assessed. The fourth recording was carried out at the end of the third week and the patient re-assessed. Finally, the patient was told he had, in reality, received three different drugs and he was asked to rate the three weeks of treatment in order of efficacy.

Three patients dropped out of the trial and were replaced. One, a woman of very small build, had her first 
TABLE I

PREFERENCES OF PATIENTS

Patient Number (chronologically)

Chlordiazepoxide Given (week)
Total Daily Dosage (mg.)

Preference two doses of $100 \mathrm{mg}$. of amylobarbitone sodium and slept most of the day. On waking, she felt drowsy and confused and asked to withdraw from the trial. The other two patients were on placebo when withdrawn; one became much more depressed, the other increasingly anxious.

STATISTICAL ANALYSIS The analyses of variance of the physiological and rating scale data were complicated because of the incomplete block design; they were based on the type I analysis set out by Cochran and Cox (1957). In essence, treatment effects were estimated against weighted within-patient variances. If the treatment effects were significant, further analyses were carried out to compute dose-effect curves, relative potencies, and fiducial limits (Finney, 1964).

\section{RESULTS OF PHYSIOLOGICAL MEASURES}

TOTAL CONDUCTANCE CHANGE This variable, the change in log conductance level from the beginning to the end of the experiment, showed significant treatment effects. An F-ratio of 7.86 was obtained (4,54 degrees of freedom, $P<0.001)$. Using $t$ tests, significant differences were found between placebo and the lower dose levels of amylobarbitone sodium and chlordiazepoxide, and between the lower dose levels and the upper dose levels, and, of course, between the placebo and the upper dose levels. The differences between the drugs within each dose level were small and not significant.

The dose-effect curves are plotted in Figure 3. At each dose level, the chlordiazepoxide had slightly more effect. Although the effects appear to follow curvilinear courses, the statistical analysis did not show deviations from rectilinearity for either dose effect curve. The regression equation of total conductance change (effect $Y_{A}$ ) on total daily dose of amylobarbitone sodium $\left(\mathrm{X}_{\mathrm{A}}\right)$ is $\mathrm{Y}_{\mathrm{A}}=-66.7+$ $0.41 X_{A}$. Similarly, for chlordiazepoxide, the regression equation for effect on dose is $\mathrm{Y}_{\mathrm{c}}=-66 \cdot 7$ $+2 \cdot 96 \mathrm{X}_{\mathrm{C}}$. The relative potency $(\mathrm{R})$, milligram for milligram of the two drugs, is given by the ratio of the two regression slopes, hence the term 'slope-ratio bioassay'. Thus, $R=0.41 / 2.96=0.139$. Therefore, a total daily dose of $300 \mathrm{mg}$. of amylobarbitone sodium is equivalent to $300 \times 0.139=41.5 \mathrm{mg}$. of chlordiazepoxide daily. By routine bioassay calculations (Finney, 1964), the 0.05 fiducial limits were $26.1 \mathrm{mg}$. and $60.9 \mathrm{mg}$. In other words, there is only a one in twenty chance that $300 \mathrm{mg}$. of barbiturate

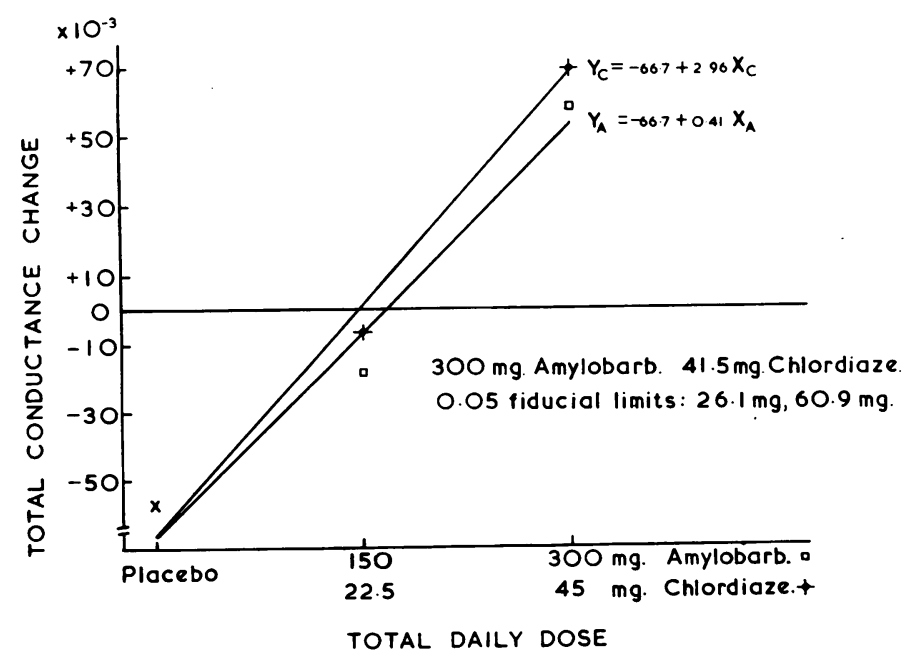

FIG. 3. Slope-ratio bioassay for 'total conductance change'. 
is equivalent to an amount of chlordiazepoxide whose value lies outside those limits.

H-SCORES The F-ratio for treatment effects on the rate of habituation of the psychogalvanic reflexes was 6.96 ( $P<0.001)$. Again, there were significant differences between the placebo and the lower dosages of both drugs and between the dosage levels but no significant differences between drugs within dosage levels.

In Fig. 4 are depicted the dose-effect curves. At the lower dosage level, the barbiturate has more effect than chlordiazepoxide in accelerating the rate of habituation whereas at the upper dosage levels, the reverse holds. On calculation of the dose-effect curves, chlordiazepoxide had the more powerful effect statistically. By calculation, $300 \mathrm{mg}$. of amylo- barbitone sodium is equivalent to $35.4 \mathrm{mg}$. of chlordiazepoxide with the 0.05 fiducial limits at $23.4 \mathrm{mg}$. and $49.8 \mathrm{mg}$.

FLUCTUATIONS AT END The third variable analysed, the number of spontaneous skin conductance fluctuations during eight 40 -second periods in the last quarter of the recording session, gave an F-ratio of 9.52 (P $<0.001)$. Similar differences between dosage levels were found as for the first two variables. The two regression lines for effect on dose lie close together (Fig. 5). The equivalent dose to $300 \mathrm{mg}$. of amylobarbitone sodium was $44.4 \mathrm{mg}$. of chlordiazepoxide; the 0.05 fiducial limits were $32.4 \mathrm{mg}$. and $61 \cdot 2 \mathrm{mg}$.

DISCRIMINANT-FUNCTION SCORES (D-SCORES) The fourth variable studied was the discriminant-
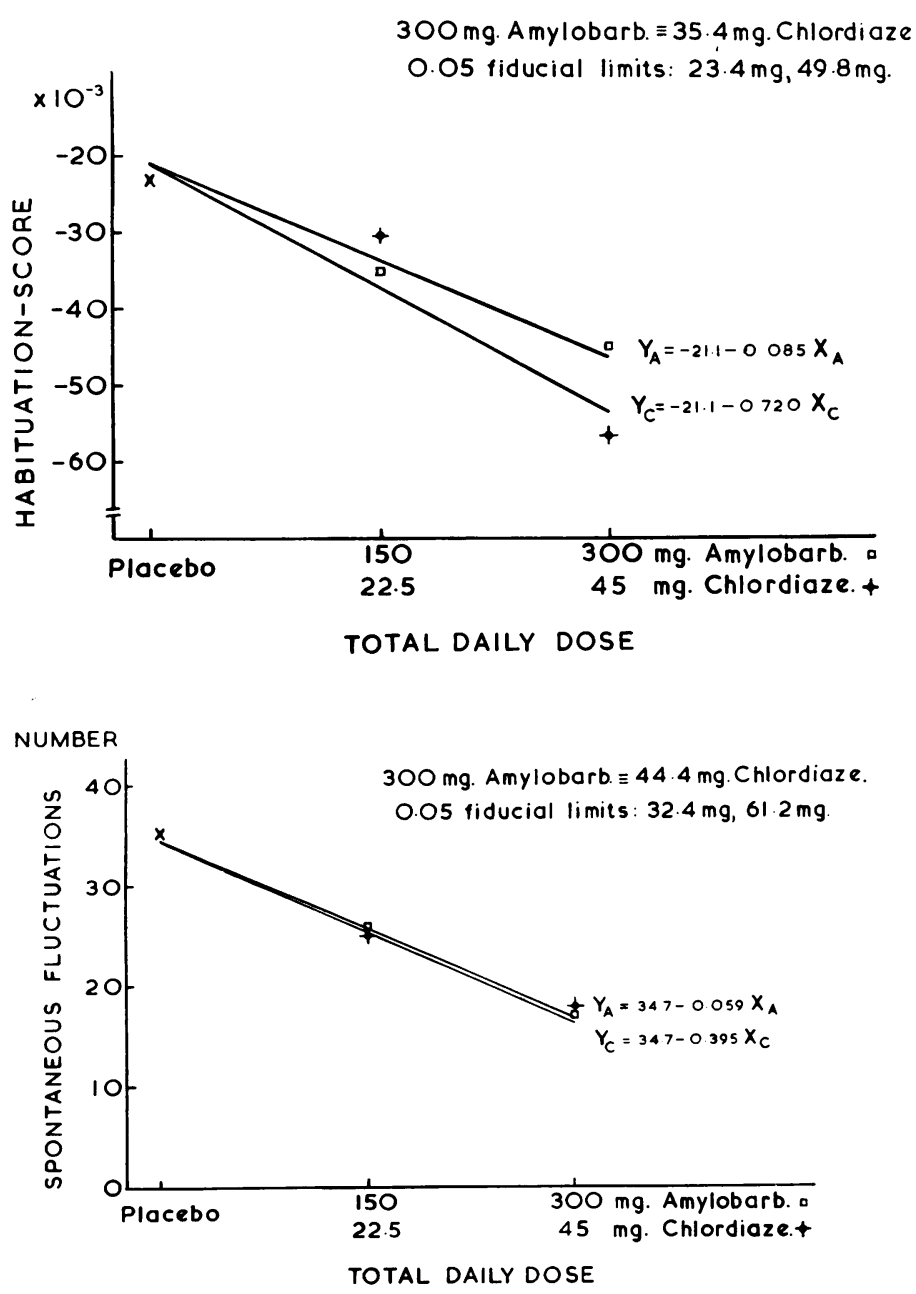

FIG. 4. Slope-ratio bioassay for $\mathrm{H}$-score

FIG. 5. Slope-ratio bioassay for 'fluctuations at end'. 


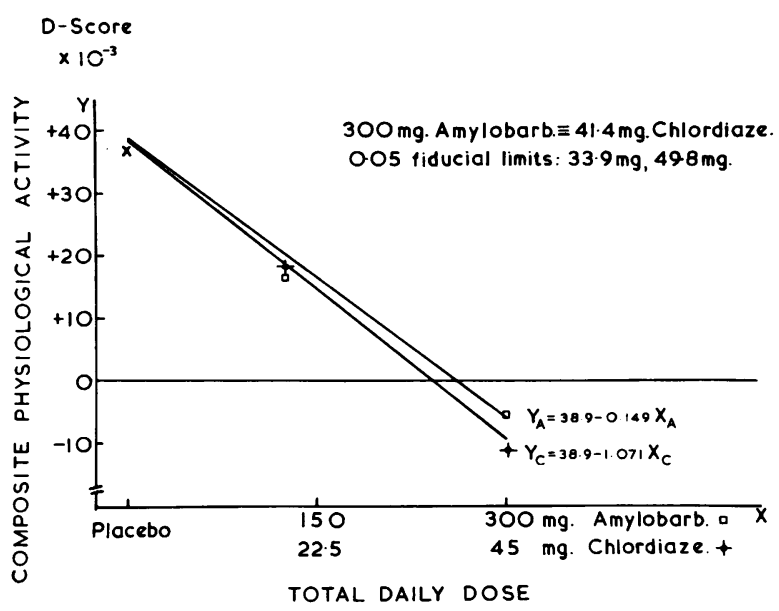

FIG. 6. Slope-ratio bioassay for D-score.

function score, a compound of the other three variables. Each set of three variables was substituted in the discriminant-function equation. The D-scores were analysed and gave an F-ratio of 27.75 (P $<0.001$ ), by far the highest F-ratio for treatment effects in the slope-ratio assay series.

From the regression equations (Fig. 6), $300 \mathrm{mg}$. of amylobarbitone sodium was equivalent to $41.4 \mathrm{mg}$. of chlordiazepoxide. The 0.05 fiducial limits were $33.9 \mathrm{mg}$. and $49.8 \mathrm{mg}$.

\section{RESULTS OF CLINICAL MEASURES}

DAILY RATINGS BY PATIENTS These were calculated as differences from baseline, positive scores indicating improvement. In Table II are set out the relevant data. The means (adjusted for incomplete block design) are shown for each treatment for each symptom category. The F-ratios and levels of significance for treatment effects are given. All the F-ratios were too low to allow the computation of useful dose-effect curves, relative potencies, and fiducial limits. However, comparisons between the means could be carried out and in the last column of
Table II are displayed the values which are the minimum significant differences between means, that is, the difference between any two means has to equal or be greater than that value in order to be significant at the 0.05 level.

For physical symptoms, the ascending order of efficacy was placebo, $22.5 \mathrm{mg}$./day of chlordiazepoxide, $150 \mathrm{mg}$./day, $300 \mathrm{mg}$./day of amylobarbitone sodium, and $45 \mathrm{mg}$./day of chlordiazepoxide. There were significant differences between placebo and the higher doses of both drugs, and between the two doses of chlordiazepoxide. There were no significant within-dose-level differences between the two drugs.

The placebo had least effect on general symptoms of anxiety followed in order by amylobarbitone sodium $150 \mathrm{mg}$., chlordiazepoxide $22.5 \mathrm{mg}$., amylobarbitone sodium $300 \mathrm{mg}$, and chlordiazepoxide $45 \mathrm{mg}$. There were significant differences between placebo and the higher doses of both drugs, and between the lower dose of barbiturate and the upper dose of chlordiazepoxide. Again, there were no significant intra-dose level differences between the two drugs but the trend is for chlordiazepoxide to be marginally superior.

Symptoms of situational anxiety were also significantly altered by the treatments. Placebo and the lower dose of chlordiazepoxide were least effective. The higher dose of chlordiazepoxide and lower dose of barbiturate were next with the upper dose of barbiturate being most useful. Significant differences were found between placebo and both doses of barbiturate and the upper dose of chlordiazepoxide. The lower dose of chlordiazepoxide was significantly less effective than both doses of barbiturate and the higher dose of chlordiazepoxide. It appears that the lower dose of chlordiazepoxide is ineffective against symptoms of situational anxiety.

There were no significant treatment effects on depressive symptoms but there is some suggestion in the data that chlordiazepoxide may be superior to amylobarbitone sodium in this respect.

WEEKLY RATINGS BY PSYCHIATRIST The results are shown in Table III. Significant treatment effects

TABLE II

DAILY RATING OF SYMPTOM CATEGORIES

\begin{tabular}{|c|c|c|c|c|c|c|c|c|c|}
\hline \multirow{3}{*}{$\begin{array}{l}\text { Symptom } \\
\text { Category }\end{array}$} & \multirow{3}{*}{$\begin{array}{l}\text { No. of } \\
\text { Patients } \\
\text { with } \\
\text { Symptoms }\end{array}$} & \multicolumn{5}{|c|}{ Mean Changes from Base-line $(\mathrm{cm})}$. & \multirow{3}{*}{$\begin{array}{l}F \text { ratio } \\
(4,54 \text { d.f. })\end{array}$} & \multirow{3}{*}{$\boldsymbol{P}$} & \multirow{3}{*}{$\begin{array}{l}0.05 \\
t \text { Test } \\
\text { Difference }\end{array}$} \\
\hline & & \multirow{2}{*}{ Placebo } & \multicolumn{4}{|c|}{ Total Daily Dose of Drug (mg.) } & & & \\
\hline & & & $\begin{array}{l}\text { Amylobarbi- } \\
\text { tone Sodium } \\
150\end{array}$ & $\begin{array}{l}\text { Chlordiaz- } \\
\text { epoxide } \\
22 \cdot 4\end{array}$ & $\begin{array}{l}\text { Amylobarbi- } \\
\text { tone Sodium } \\
300\end{array}$ & $\begin{array}{l}\text { Chlordiaz- } \\
\text { epoxide } \\
45\end{array}$ & & & \\
\hline $\begin{array}{l}\text { Physical } \\
\text { General } \\
\text { Situational } \\
\text { Depressive }\end{array}$ & $\begin{array}{l}30 \\
19 \\
24 \\
29\end{array}$ & $\begin{array}{l}2.5 \\
1.8 \\
1.4 \\
2.0\end{array}$ & $\begin{array}{l}3 \cdot 1 \\
2 \cdot 1 \\
2 \cdot 5 \\
1 \cdot 8\end{array}$ & $\begin{array}{l}2 \cdot 8 \\
2 \cdot 3 \\
1 \cdot 5 \\
2 \cdot 5\end{array}$ & $\begin{array}{l}3 \cdot 5 \\
2 \cdot 6 \\
2.9 \\
2 \cdot 6\end{array}$ & $\begin{array}{l}3.9 \\
3.0 \\
2.6 \\
3.4\end{array}$ & $\begin{array}{l}3 \cdot 11 \\
3 \cdot 05 \\
4 \cdot 10 \\
2 \cdot 00\end{array}$ & $\begin{array}{c}<0.025 \\
=0.025 \\
<0.01 \\
\text { N.S. }\end{array}$ & $\begin{array}{l}0.9 \\
0.8 \\
1 \cdot 0 \\
-\end{array}$ \\
\hline
\end{tabular}


TABLE III

WEEKLY RATING OF SYMPTOM CATEGORIES

\begin{tabular}{|c|c|c|c|c|c|c|c|c|c|}
\hline \multirow{3}{*}{$\begin{array}{l}\text { Symptom } \\
\text { Category }\end{array}$} & \multirow{3}{*}{$\begin{array}{l}\text { No. of } \\
\text { Patients } \\
\text { with } \\
\text { Symptoms }\end{array}$} & \multicolumn{5}{|c|}{ Mean Changes from Pre-drug State (9-point scale) } & \multirow{3}{*}{$\begin{array}{l}\text { F ratio } \\
(4,54 \text { d.f. })\end{array}$} & \multirow{3}{*}{$P$} & \multirow{3}{*}{$\begin{array}{l}0.05 \\
t \text { Test } \\
\text { Difference }\end{array}$} \\
\hline & & \multirow{2}{*}{ Placebo } & \multicolumn{4}{|c|}{ Total Daily Dose of Drugs (mg.) } & & & \\
\hline & & & $\begin{array}{l}\text { Amylobarbi- } \\
\text { tone Sodium } \\
150\end{array}$ & $\begin{array}{l}\text { Chlordiaz- } \\
\text { epoxide } \\
22 \cdot 5\end{array}$ & $\begin{array}{l}\text { Amylobarbi- } \\
\text { tone Sodium } \\
300\end{array}$ & $\begin{array}{l}\text { Chlordiaz- } \\
\text { epoxide } \\
45\end{array}$ & & & \\
\hline Physical & 30 & 0.9 & 1.9 & $2 \cdot 1$ & $2 \cdot 2$ & $2 \cdot 7$ & $3 \cdot 75$ & $<0.01$ & 0.9 \\
\hline General & 19 & 0.4 & 0.6 & 0.6 & 0.8 & $1 \cdot 3$ & $2 \cdot 28$ & N.S. & - \\
\hline Situational & 24 & 0.2 & $1 \cdot 3$ & 0.9 & $1 \cdot 4$ & $1 \cdot 3$ & $2 \cdot 53$ & almost 0.05 & 0.9 \\
\hline Depressive & 29 & 0.5 & 0.9 & $1 \cdot 2$ & 1.4 & 1.9 & 1.07 & N.S. & - \\
\hline
\end{tabular}

were found for physical symptoms. The only significant difference was that between results for the placebo and all the other treatments. The nonsignificant trend was for chlordiazepoxide to be more effective than amylobarbitone sodium.

No significant treatment effects emerged in the category of patients with general anxiety. For situational symptoms, the treatment effects were almost significant, an $F$ ratio of 2.55 being necessary. Both dose levels of amylobarbitone sodium and the upper dose level of chlordiazepoxide were more effective than the placebo but there was no firm evidence that barbiturate was the more effective drug.

Depressive symptoms did not yield any significant drug effects but again there is a hint in the data that chlordiazepoxide was slightly more effective.

PLACEBO EFFECTS It may be seen from Tables II and III that all the treatment scores are positive, suggesting that even the placebo could cause some amelioration of symptoms from the pre-drug period. The changes from the period before the drug was given were analysed statistically to determine whether they were significant and the results are shown in Table IV. All the symptom categories as rated daily were significantly improved by placebo; according to the weekly ratings, however, the changes from before the drug were not significant. The placebo data were further analysed to ascertain if there was a significant occasion effect, e.g., if placebo had more effect given as the first treatment than the second or third. No significant effects were found.

TABLE IV Clinical CHANGeS ON PLACEBo

\begin{tabular}{lcccc}
$\begin{array}{l}\text { Symptom } \\
\text { Category }\end{array}$ & \multicolumn{1}{l}{ Daily Scores } & \multicolumn{3}{c}{ Weekly Scores } \\
\cline { 2 - 5 } & t-Value $(54$ d.f.) & $P$ & $t$-Value $(54$ d.f.) & $P$ \\
\hline Physical & 5.49 & $<0.001$ & $<1$ & N.S. \\
General & 4.54 & $<0.001$ & $<1$ & N.S. \\
Situational & 2.99 & $<0.01$ & $<1$ & N.S. \\
Depressive & 3.23 & $<0.01$ & $<1$ & N.S.
\end{tabular}

DRUG PREFERENCES OF PATIENTS Without being told the actual drugs used, the patients were asked their order of preference of their three weeks of treatment which were thus assigned ranks 1,2 , and 3 . If a patient was unable to decide between two weeks, both were ranked 1.5 or 2.5 appropriately. No patient was unable to decide between the three weeks.

The ranks were totalled for each treatment. The minimum possible total, i.e., most preferred drug, was 18; the maximum total was 54 . If all preferences had been random, each treatment total sum of ranks would have been around 36 . The actual totals़े were placebo $45 \cdot 5$, lower chlordiazepoxide dose $40 \cdot 5$ 융 lower barbiturate dose 34, upper barbiturate dose 33 , and upper dose of chlordiazepoxide 27. These sums of ranks are significantly non-random (W $=$ $0 \cdot 25 ; \mathrm{F}=4.22 ; 4,48$ df.; $\mathrm{P}<0.01$; Kendall, 1962)

The sum of ranks for occasion was first week $63 \cdot 5$, second week 57 , and third week 59.5. These sums of ranks were not significantly different from random, showing that there was no preference by the patients for any particular week's treatment.

Nine patients received the higher dosage levels of both drugs: three preferred barbiturate, five chlordiazepoxide, and one was undecided. Of the nine patients receiving the lower dosages, five preferred barbiturate, three chlordiazepoxide and, again, one was unable to decide.

INCIDENCE OF SIDE EFFECTS Twenty-one of the 30 patients complained of side effects from at least one of the treatments. Nineteen were drowsy during the day time, one complained of a 'thick-headed feeling', and one of being 'light-headed and dizzy'.

The incidence of these reported side effects for each treatment is depicted graphically in Figure 7. The close correspondence between the two dose effect curves is evident. The incidence for the upper dosage levels is over $50 \%$ but no patient was seriously inconvenienced by the somnolence except the woman who withdrew. Another woman had to retire early every evening but welcomed this as a relief from her usual persistent insomnia. 


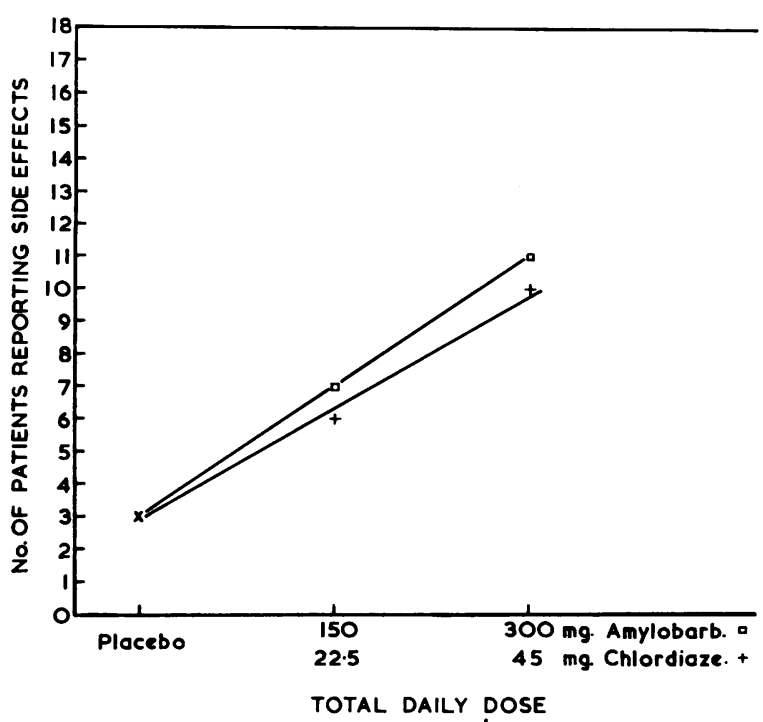

FIG. 7. Incidence of side effects.

\section{DISCUSSION}

The staircase assay was essential as a preliminary in order to be able to set the approximate dosage ratio for the full-scale assay. If the dosage ratio were badly chosen, the upper dose of one drug might have less effect than the lower dose of the other drug and the slope-ratio bioassay would have been invalidated. Obviously, only one variable could be used in the staircase assay to establish the dosage ratio; the D-score, a measure of composite physiological activity, was chosen because it was known previously to yield the most significant effects for a sedative drug (Wing and Lader, 1965). The dosage ratio derived from the physiological recordings tallied with the overall preferences of the patients. Furthermore, from previous clinical experience with chlordiazepoxide and amylobarbitone sodium, the derived dosage ratio appeared reasonable.

The most useful property of the staircase assay is that it concentrates experiments in the operative dosage range, i.e., in the region of approximate equality of effects of the two drugs. Its main disadvantage is that each patient's drug trial must terminate before the next patient's can be started. However, it is possible to overlap experiments by working in from both ends of the dosage range simultaneously. The staircase assay was ended when a regression line could be calculated with limits of confidence from which the dosage ratio for the fullscale bioassay could be chosen with only a one in twenty chance of invalidating that bioassay design.

Both assays used 'repetitive sampling' in that more than one drug treatment was given to each patient. This technique has been criticized (e.g. Heilizer, 1960 ) on the grounds that the second and subsequent weeks' treatment effects are confounded with 'carryover' or withdrawal effects from the previous week's therapy. In the present experiments, the drugs used are relatively short-acting so that residual effects would be minimal after a few days. The recordings were taken at the end of the week and the clinical self ratings were analysed for the last three days of each treatment only. Furthermore, in the slope-ratio bioassay, the experiment was designed so that each treatment followed every other one an equal number of times although, because of the incomplete block design, it was not practicable to evaluate any carryover effects.

The main assay was a formal two-plus-two-plusone assay, i.e., two doses of two drugs and a placebo. The design was chosen because rectilinear doseeffect curves with a barbiturate had been obtained previously in normals (Lader, 1964), Also, placebo effects could be analysed.

One method of carrying out the assay would have been to give each patient one treatment only. This would have entailed vast numbers of comparable patients: effects of treatment would have been estimated against between-patient variance which for our physiological measures is invariably several times the within-patient variance. Furthermore, the patients would not have been able to state any preferences. The other extreme, to have given each patient all five treatments, would have been a lengthy procedure, tiring for the patients, and treatment preferences would have been difficult for the patients to decide. Therefore, a compromise was decided on and each patient received three out of five treatments. By this means, the several-fold precision of using within-patient comparisons to assess effects of treatments was retained and it was reasonably easy for patients to decide the order of efficacy of the three treatments. The disadvantage was that the more complicated aspects of statistical analysis of incomplete block designs are often less fully developed than, say, latin square designs.

The patients in the study all had symptoms of anxiety but the criteria for inclusion were widened from the previous trial (Lader and Wing, 1964) in that patients suffering from anxiety with depression and with previously abnormal personalities were included. But in all patients, the consultants in charge regarded sedatives as being indicated.

The result of the physiological measures bioassays was that useful dose-effect curves, comparisons, and fiducial limits could be calculated. In the doses used, chlordiazepoxide was slightly more effective in all the physiological variables. The most accurate 
assay was that utilizing the D-scores: $300 \mathrm{mg}$. a day of amylobarbitone sodium was equivalent to $41 \cdot 4$ mg. a day of chlordiazepoxide. That is, $65 \mathrm{mg}$. (1 grain) of amylobarbitone sodium is equivalent to $9 \mathrm{mg}$. of chlordiazepoxide. This is in accord with general clinical experience.

The variables selected for the assay were known from the previous experiment to be sensitive to barbiturate effect (Wing and Lader, 1965). It might be argued that this would introduce a bias against chlordiazepoxide. There is no evidence that barbiturates or chlordiazepoxide have any selective action, either centrally or peripherally mediated, against sweat-gland activity and hence skin conductance. Also, the D-score equation was obtained originally from pre-drug data and would not be expected to have a bias either way.

The drugs had significant effects on the daily self ratings for the physical symptoms, the general symptoms, and the situational anxiety symptoms. For the weekly ratings, treatment effects were significant for physical symptoms and almost significant for situational anxiety symptoms. Of course, the mean drug effects obscure individual changes. It would be expected that some patients, impressed by relief of any symptom, would rate themselves greatly improved whereas others, expecting marked amelioration of symptoms, would underrate any improvement. But, at weekly interviews, the true change in any symptom would be more accurately assessed. As placebo effects were significant for daily but not for weekly ratings, and, also, symptom changes were greater for daily than for weekly ratings, it appears that, in general, patients tend to overestimate their improvement. The theoretical advantages, disadvantages, and assumptions inherent in using rating scales will not be discussed here as this study was primarily concerned with the comparison of two drugs.

However, not only was a bioassay comparison of the two drugs attained but it so happened that the doses used turned out to be almost equivalent. Therefore, it was possible to compare the clinical effects of the two drugs in order to state which was superior. Chlordiazepoxide was the preferred drug at the upper dosage but this was nowhere near significance. At the lower dosage, the barbiturate tended to be preferred. Indeed, the total rank preferences for the two drugs were equal at 67. It may be concluded that, as far as overall preferences are concerned, there was no difference between the two drugs.

There seemed to be some tendency for the lower dose of chlordiazepoxide to have less effect than would have been predicted from the effects of placebo and the upper dose. Thus, chlordiazepoxide's dose-effect curve may be somewhat S-shaped. However, there was no statistical evidence for this so the drug comparison remained valid.

It is just possible that there were some slight differences between the drugs with respect to their actions on the various categories of symptom. Thus, amylobarbitone sodium appeared more effective in combating situational anxiety whereas chlordiazepoxide in the upper dose had some antidepressive effect, albeit not significantly. Also, this dose of chlordiazepoxide was somewhat more effectual than the barbiturate against physical symptoms. As these are probably the easiest for a patient to assess, this may have accounted for this drug dose being most preferred. Anyway, it was slightly more potent on the physiological measures.

The side-effects of the drugs were similar in character and ostensibly equal in number. There was a fairly high incidence of minor effects such as mild drowsiness. Doubtless, the incidence would have been lessened if the dosages had been given in terms of body weight or 'metabolically active mass', but this type of dosage schedule was impracticable.

Thus, the two drugs, amylobarbitone sodium and chlordiazepoxide, were equivalent in a ratios milligram for milligram, of about seven to one. In creased potency, of course, is not a therapeutio advantage in itself. As far as we were able to ascer: tain, the physiological and clinical effects of the two drugs were identical as was the incidence an nature of their side effects. We were unable to discerr any specific 'anti-anxiety effect' of chlordiazepoxide in our patients. In our opinion, therefore, chlor= diazepoxide is a sedative drug with therapeutic properties indistinguishable from the barbiturates. The decision as to which drug to prescribe must be made on secondary considerations. One is cost; amylobarbitone sodium, $65 \mathrm{mg}$., 4 shillings for 100 ; chlordiazepoxide, $10 \mathrm{mg}$., 20 shillings for 100 . Another is the important advantage of chlordiazepoxide in its safety when a patient takes a massive overdose with suicidal intent. Against this must be weighed the disadvantage of a drug which has been in use a relatively short time even though during that time it has been very extensively prescribed.

Summarizing, chlordiazepoxide is a sedative drug similar in action to the older well-tried barbiturates, and like them of only limited use in the treatment of patients with anxiety states. No doubt, in time, it will find its appropriate place in the armamentarium of psychiatric drugs, that of a sedative free from the risks of suicidal overdosage.

In an earlier paper (Lader and Wing, 1964), we outlined a theory of the mechanism of pathological anxiety based on the relationship between rate of habituation and general activity of the central 
nervous system. Thus, in the general population, the rate of habituation was regarded as reflecting a property of the central nervous system distributed along a continuum with any individual's locus on that continuum mainly genetically determined. In normal people, stressful situations cause a rise in level of activity of the central nervous system but adaptation occurs and the level quickly falls. In individuals with defective habituation and adaptation, stressful stimuli cause a greatly prolonged rise in activity of the central nervous system. In the present experiments, the physiological measures were affected in an orderly way by both the drugs. If it were a specific 'anti-anxiety' drug chlordiazepoxide might be expected to have a more powerful effect on the rate of habituation than on the other variables, assuming the theory of anxiety outlined above to be roughly true. The slight trend in that direction was not nearly significant and this correlates with the lack of specific clinical 'anti-anxiety' effect of chlordiazepoxide as compared with the barbiturate. The parallelism demonstrated between the physiological and clinical findings is consistent with the hypothesis.

In conclusion, the present experiments have demonstrated that pharmacological techniques can be applied to therapeutic problems in clinical psychiatry. This applies not only in circumstances where the parameters of drug action are fairly sensitive, e.g., the D score, but also for the relatively crude clinical measures. Indeed, the more complex the clinical problem, the more necessary is it to take full advantage of the techniques developed in those medical disciplines in which quantitative methods have been more highly developed.

\section{SUMMARY}

In a preliminary 'staircase' bioassay, eight patients with anxiety states received two weeks of drug therapy, namely, amylobarbitone sodium $65 \mathrm{mg}$. t.d.s. one week and chlordiazepoxide (Librium) the other week, the dose varying from patient to patient. At the end of each week, the palmar skin resistance was recorded during a standard habituation procedure consisting of a 10-minute rest period followed by 20 identical auditory stimuli occurring at intervals ranging from 45 to 80 seconds. A measure of 'composite physiological activity' was derived from three skin conductance variables. The dose of chlordiazepoxide, which had an equivalent effect to that of the fixed dose of barbiturate on this measure, was calculated. This allowed the selection of the appropriate doses of the two drugs for the full-scale bioassay.

The main bioassay was of a slope-ratio two-plustwo-plus-one design. The five treatments were amylobarbitone sodium $50 \mathrm{mg}$. t.d.s. and $100 \mathrm{mg}$. t.d.s., chlordiazepoxide $7.5 \mathrm{mg}$. t.d.s. and $15 \mathrm{mg}$. t.d.s., and placebo. Thirty patients each received three out of the five treatments in a fully balanced randomized incomplete block design, each for one week with the double-blind method.

The palmar skin resistance with the habituation procedure was recorded at the end of each week. Three variables and the measure of 'composite physiological activity', derived from combining them, showed highly significant treatment effects enabling dose-effect curves, equivalent dosages, and fiducial limits to be calculated.

The patients daily rated their symptoms, which could be classified as physical, i.e., autonomic or muscular, general feelings of anxiety, situational anxiety, and depressive symptoms. Weekly ratings of changes in the same symptoms were made at interview after the physiological tests. Significant treatment effects were found for several symptom categories but no consistent differences were discerned between the two drugs. Furthermore, the side effects of the two drugs were similar in nature and equal in prevalence.

Chlordiazepoxide is a sedative drug with therapeutic actions in patients with anxiety states similar to and as limited as those of amylobarbitone sodium.

This work was supported by grant no. MY-3561 from the National Institute of Mental Health of the U.S. Public Health Service. We are indebted to Professor H. O. Schild, Dr. Michael Shepherd, Dr. A. Maxwell, and to Miss M. W. Hill and her staff. Thanks are also due to Roche Products Ltd. for supplying the special tablets used in the trial.

\section{REFERENCES}

Brownlee, K. A., Hodges, J. L., and Rosenblatt, M. (1953). The upand-down method with small samples. J. Amer. stat. Ass., 48, 262-277.

Cochran, W. G., and Cox, G. M. (1957). Experimental Designs, 2nd ed. Wiley, New York.

Dixon, W. J., and Mood, A. M. (1948). A method for obtaining and analyzing sensitivity data. J. Amer. stat. Ass., 43, 109-126.

Editorial (1962). Drugs for anxiety. Brit. med. J., 1, 38-39.

Finney, D. J. (1964). Statistical Method in Biological Assay, 2nd ed. Griffin, London.

Fisher, R. A. (1954). Statistical Methods for Research Workers, 12th ed. Oliver and Boyd, Edinburgh.

Heilizer, F. (1960). A critical review of some published experiments with chlorpromazine in schizophrenic, neurotic, and normal humans. J. chron. Dis., 11, 102-148.

Jenner, F. A., Kerry, R. J., and Parkin, D. (1961). A controlled trial of methaminodiazepoxide (chlordiazepoxide, 'Librium') in the treatment of anxiety in neurotic patients. J. ment. Sci., $107,575-82$.

Kendall, M. G. (1962). Rank Correlation Methods, 3rd ed. Griffin, London.

Lader, M. H. (1964). The effect of cyclobarbitone on the habituation of the psycho-galvanic refiex. Brain, 87, 321-340.

_, and Wing, Lorna (1964). Habituation of the psycho-galvanic reflex in patients with anxiety states and in normal subjects. J. Neurol. Neurosurg. Psychiat., 27, 210-218.

Snedecor, G. W. (1956). Statistical Methods, 5th ed. Iowa State College Press, Ames, Iowa.

Wing, Lorna, and Lader, M. H. (1965). Physiological and clinical effects of amylobarbitone sodium therapy in patients with anxiety states. J. Neurol. Neurosurg. Psychiat., 28, 78-87. 